Article

\title{
Evaluation of Industrial Urea Energy Consumption (EC) Based on Life Cycle Assessment (LCA)
}

\author{
Longyu Shi ${ }^{1}$, Lingyu Liu ${ }^{1,2}$, Bin Yang ${ }^{1,2,3}$, Gonghan Sheng ${ }^{4}$ and Tong $X u^{1,5, *}$ \\ 1 Key Laboratory of Urban Environment and Health, Institute of Urban Environment, Chinese Academy of \\ Sciences, Xiamen 361021, China; lyshi@iue.ac.cn (L.S.); lyliu@iue.ac.cn (L.L.); yangbin@gzata.cn (B.Y.) \\ 2 University of Chinese Academy of Sciences, Beijing 100049, China \\ 3 Guizhou Academy of Testing and Analysis, Guiyang 550002, China \\ 4 Faculty of Forestry, The University of British Columbia, Vancouver, BC V6T 1Z4, Canada; \\ shenggonghan@hotmail.com \\ 5 Centre for Environment, Energy and Natural Resource Governance, Department of Land Economy, \\ University of Cambridge, Cambridge CB2 3GZ, UK \\ * Correspondence: tx224@cam.ac.uk; Tel.: +44-0790-0880-477
}

Received: 30 March 2020; Accepted: 2 May 2020; Published: 7 May 2020

check for updates

\begin{abstract}
With the increasingly prominent environmental problems and the decline of fossil fuel reserves, the reduction of energy consumption (EC) has become a common goal in the world. Urea industry is a typical energy-intensive chemical industry. However, studies just focus on the breakthrough of specific production technology or only consider the EC in the production stage. This results in a lack of evaluations of the life cycle of energy consumption (LcEC). In order to provide a systematic, scientific, and practical theoretical basis for the industrial upgrading and the energy transformation, LcEC of urea production and the greenhouse gas (GHG) emissions generated in the process of EC are studied in this paper. The results show that the average LcEC is about $30.1 \mathrm{GJ} / \mathrm{t}$ urea. The $\mathrm{EC}$ of the materials preparation stage, synthesis stage, and waste-treatment stage $\left(\mathrm{EC}_{\mathrm{RMP}}\right.$, $\mathrm{EC}_{\mathrm{PP}}, \mathrm{EC}_{\mathrm{WD}}$ ) is about $0.388 \mathrm{GJ} / \mathrm{t}$ urea, $24.8 \mathrm{GJ} / \mathrm{t}$ urea, and $4.92 \mathrm{GJ} / \mathrm{t}$ urea, accounting for $1.3 \%, 82.4 \%$, and $16.3 \%$ of LcEC, respectively. Thus, the synthesis stage is a dominant energy-consumer, in which $15.4 \mathrm{GJ} / \mathrm{t}$ urea of energy, accounting for $62.0 \%$ of $\mathrm{EC}_{\mathrm{pp}}$, supports steam consumption. According to the energy distribution analysis, it can be concluded that coal presents the primary energy in the process of urea production, which supports $94.4 \%$ of LcEC. The proportion of coal consumption is significantly higher than that of the average of $59 \%$ in China. Besides, the GHG emissions in the synthesis stage are obviously larger than that in the other stage, with an average of $2.18 \mathrm{t}$ eq. $\mathrm{CO}_{2} / \mathrm{t}$ urea, accounting for $81.3 \%$ of the life cycle of GHG (LcGHG) emissions. In detail, $\mathrm{CO}_{2}$ is the dominant factor accounting for $90.0 \%$ of $\mathrm{LcGHG}$ emissions, followed by $\mathrm{CH}_{4}$, while $\mathrm{N}_{2} \mathrm{O}$ is negligible. Coal is the primary source of $\mathrm{CO}_{2}$ emissions. The severe high proportion of coal consumption in the life cycle of urea production is responsible for this high $\mathrm{CO}_{2}$ content of GHG emissions. Therefore, for industrial urea upgrading and energy transformation, reducing coal consumption will still be an important task for energy structure transformation. At the same time, the reformation of synthesis technologies, especially for steam energy-consuming technology, will mainly reduce the EC of the urea industry. Furthermore, the application of green energy will be conducive to a win-win situation for both economic and environmental benefits.
\end{abstract}

Keywords: energy consumption (EC); evaluation; urea industry; life cycle assessment (LCA); greenhouse gas (GHG) emissions 


\section{Introduction}

Climate change has become a critical issue that restricts global sustainable development [1]. The greenhouse gas (GHG) emissions from fossil fuel consumption are world-widely considered as a crucial source of climate change [2]. Reducing energy consumption (EC) is believed effective to save energy, protect the environment, and achieve economic sustainability [3,4]. It is in line with the concept of global sustainability and has been gradually ratified by global decision-makers $[5,6]$. It has become one of the most critical topics in global economics [7].

The industrial sector provides an indispensable material foundation for the survival and development of human beings. It is a powerful driving force for future social development. However, the industrial sector is considered energy-intensive [8-10], accounting for 37\% of total global EC in 2017 [11] and more than 50\% of global end-use EC in 2018 [12]. According to the International Energy Outlook (IEO) 2019, the EC of the industrial sector will increase by more than $30 \%$ from 2018 to 2050 [12]. The industrial sector includes three distinct industry types: energy-intensive manufacturing, nonenergy-intensive manufacturing, and nonmanufacturing [13]. The ongoing long-term trend of increasing production in energy-intensive manufacturing drives the most rapid growth of EC in the industrial sector [11]. The chemical industry is one of the representatives and the largest energy consumer among energy-intensive industries. The share of energy use in the chemical industry accounts for $19 \%$ and $14 \%$ of the total delivered EC in the industrial sector of the Organization for Economic Cooperation and Development (OECD) countries and the non-OECD countries, respectively [13]. The share is estimated to rise to $20 \%$ in both regions in 2040 based on the IEO 2016 reference case [13]. Therefore, how to adjust the balance between economic development and the environment is a common issue for all countries to address the challenges related to energy, resources, and environment [14,15].

China's rapidly growing population and economy have driven the country to be the top energy producer and consumer [16] and $\mathrm{CO}_{2}$ emitter [2] in the world. BP Energy Outlook 2018 estimates that China will still consume around one-quarter of world energy in 2040 despite the slowing growth of energy demand [17]. Moreover, as one of the largest chemical manufacturing countries in the world $[18,19]$, China's share of industrial energy consumption will only decrease from $29 \%$ in 2018 to $24 \%$ in 2050, according to International Energy Outlook 2019 [12]. The study of the EC of the sector, especially the energy-intensive chemical industry in China, has important implications for the industrial upgrading and transformation of energy structure in the industrial sector worldwide.

Urea is not only a critical chemical fertilizer but also a widely used industrial raw materials. The urea industry is one of the representative chemical industrial sectors in the world. Urea production in China began in 1958 [20]. China is the world's largest producer and consumer of urea, producing 61.9 million tons of urea and consuming over $55 \%$ of total urea produced along with the Southwest Asian region in 2016 [21,22]. With the growing urea demand, the EC of the urea industry has increased. It is significant to analyze the EC in the production process, estimate the situation of energy use, and find the balance between the industrial economy and environmental improvement to achieve sustainable development.

The life cycle assessment (LCA) is a "cradle-to-grave" or "gate-to-gate" evaluation of the environmental costs associated with a given product [23,24]. It differs from traditional evaluation methods such as the single-factor energy efficiency evaluation method $[25,26]$ and the total-factor energy efficiency evaluation method [27-29], in which the energy efficiency assessments are incomplete. The LCA offers a holistic view of environmental interactions that covers a range of activities from the extraction of raw materials to the production and distribution of energy, through the use, reuse, and final disposal of a product [24]. It is regarded as a common decision-support tool for both policymakers and industry experts in assessing the impacts of a product or process [24-31]. A combination of EC and GHG emissions analysis with the comparison of life cycle performance of production is conducive to the study of energy-saving and emissions reduction [32].

Most studies focus on the breakthrough of a specific production technology [33,34], or only consider the EC in the production stage [35], resulting in the lack of the evaluations of the life cycle 
energy consumption (LcEC). In this study, the LCA and the production process of the urea industry are carried out to establish a life cycle framework of industrial urea, which includes three stages: raw material production stage, production stage, and waste-treatment stage. Moreover, by using the inventory data from seven different real industrial urea operations, the LcEC of the urea industry from raw material extraction to disposal is evaluated the first time in this study. The GHG emissions generated throughout the LcEC of urea production are also estimated. This paper provides a systematic, valid, and realistic judgment on the EC and GHGs impacts of the chemical industry, which can be used as a scientific basis for future development strategies and policies to promote sustainability in the industrial sector.

\section{Evaluation Methods and Data}

\subsection{Life Cycle Framework of the Urea Production}

Urea $\left(\mathrm{NH}_{2} \mathrm{CONH}_{2}\right)$ is an important nitrogen-rich organic compound, which was initially produced via the use of inorganics by Friedrich Wöhler in 1828 [36]. In the urea factory, urea is synthesized from synthetic ammonia, which is usually produced from coal or natural gas (NG) with other materials, and $\mathrm{CO}_{2}$ [37]. The production routines mainly involve the ammonia synthesis process and urea synthesis process including air separation (likes grinding coal, industrial gasification, ash water treatment), desulfurization conversion, purification, ammonia synthesis, ammonia recovery, ammonia compression, urea synthesis, decomposition, concentration, and recovery, etc., the detailed information is available in the literature $[38,39]$.

A life cycle framework of the urea production is established based on the International Standards ISO 14040:2006 and ISO 14044:2006 [40,41], and the analysis of material and energy flows in the production process. As shown in Figure 1, the life cycle of urea production is divided into three stages: the materials preparation stage, synthesis stage, and waste-treatment stage. In the materials preparation stage, natural resources are extracted and transported to the urea plant as raw materials. In the synthesis stage, the intermediate material ammonia is synthesized using coal or natural gas at first and then used to synthesis urea with $\mathrm{CO}_{2}$. In the waste-treatment stage, waste gas, water, and residues are disposed of in several ways. 


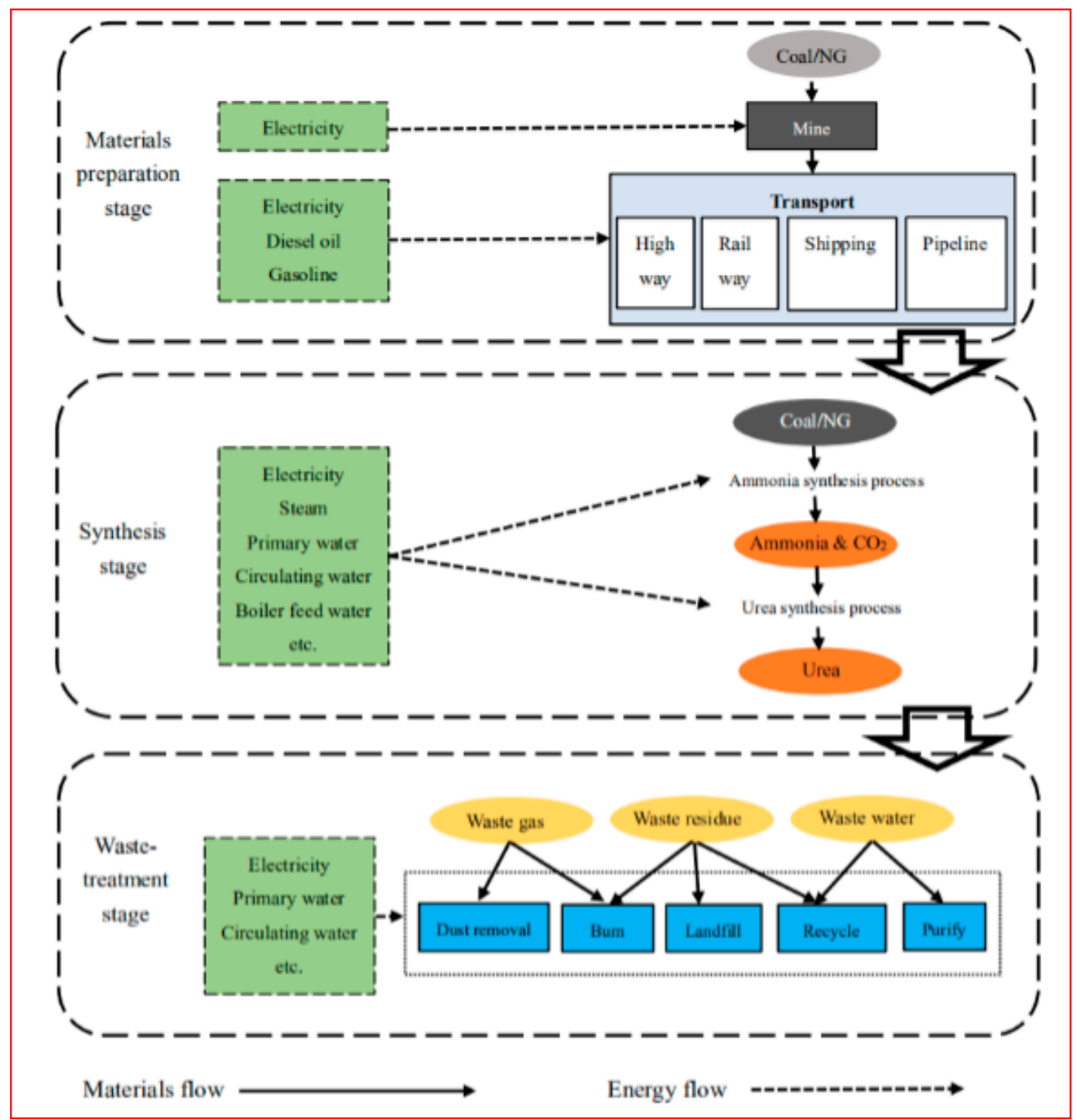

Figure 1. Life cycle framework of urea production.

\subsection{Life Cycle Energy Consumption (LcEC)}

In this study, the LcEC represents the total primary fossil fuel energy inputs in the life cycle of urea production, and the LcGHGs is calculated by the sum of GHGs $\left(\mathrm{CO}_{2}, \mathrm{CH}_{4}, \mathrm{~N}_{2} \mathrm{O}\right)$ generated by the EC of each stage.

According to the inventory analysis of LcEC in the chemical production process $[40,41]$ and the three stages defined in Figure 1, the LcEC consists of the EC of raw material preparation (EC RMP), product production $\left(\mathrm{EC}_{\mathrm{pp}}\right.$ ) and waste disposal $\left(\mathrm{EC} \mathrm{WD}_{\mathrm{WD}}\right)$, which reflects the $\mathrm{EC}$ of the material preparation stage, synthesis stage, and waste-treatment stage, respectively. It is calculated by the sum of the product of process energy consumption (PEC) and the corresponding primary fossil consumption factor (PFCF) [32,42,43], as shown in Equation (1).

$$
L c E C=E C_{R M P}+E C_{P P}+E C_{W D}=\sum_{f} \sum_{i} \sum_{j} P E C_{f, i} \times P F C F_{i, j}
$$

where $f$ represents sub-stage of raw materials preparation stage, synthesis stage, and waste-treatment stage; $i$ represents the type of process energy; $j$ represents the type of primary fossil energy input; $P E C_{f, i}$ 
represents the PEC of unit urea in the sub-stage $f$; and $P F C F_{i, j}$ represents the consumption of primary fossil $j$ to obtain $1 \mathrm{MJ}$ process energy $i$, as shown in Table 1.

The sub-stage of synthesis stage includes the whole process of material from various physical and chemical reactions to completion of chemical products, that is, processing of gasification, intermediate material synthesis, urea synthesis, and storage with process energy (e.g., circulating water, condensate consumed by energy-used medium). The energy coefficient of the energy-consumed medium is shown in Table 2.

Table 1. Primary fossil consumption factors [32,42-44].

\begin{tabular}{cccc}
\hline Process Energy & Coal (MJ/MJ) & NG (MJ/MJ) & Oil (MJ/MJ) \\
\hline Coal & 1.06 & 0.00 & 0.11 \\
Electricity & 2.86 & 0.03 & 0.37 \\
Steam & 1.38 & 0.00 & 0.01 \\
Diesel & 0.18 & 0.03 & 1.12 \\
Gasoline & 0.18 & 0.03 & 1.12 \\
\hline
\end{tabular}

Table 2. Energy coefficient of the energy-consumed medium [45].

\begin{tabular}{ccc}
\hline Types & Unit & Average Calorific Value (MJ) \\
\hline Circulating water & $\mathrm{t}$ & 4.19 \\
Softened water & $\mathrm{t}$ & 10.47 \\
Heating equipment condensate & $\mathrm{t}$ & 320.3 \\
Steam turbine condensate water & $\mathrm{t}$ & 152.8 \\
Desalted water & $\mathrm{t}$ & 96.3 \\
Deoxygenated water & $\mathrm{t}$ & 385.2 \\
Compressed air (purified) & $\mathrm{m}^{3}$ & 1.59 \\
Compressed air (Non-purified) & $\mathrm{m}^{3}$ & 1.17 \\
Steam (10.0 MPa) & $\mathrm{t}$ & 3852 \\
Steam (4.9 MPa) & $\mathrm{t}$ & 3768 \\
Steam (3.5 MPa) & $\mathrm{t}$ & 3684 \\
Steam (3.0 MPa) & $\mathrm{t}$ & 3681 \\
Steam (2.5 MPa) & $\mathrm{t}$ & 3559 \\
Steam $(1.3 \mathrm{MPa})$ & $\mathrm{t}$ & 3349 \\
Steam $(1.0 \mathrm{MPa})$ & $\mathrm{t}$ & 3182 \\
Steam $(0.6 \mathrm{Mpa})$ & $\mathrm{t}$ & 3011 \\
Steam $(0.5 \mathrm{MPa})$ & $\mathrm{t}$ & 2763 \\
Steam $(0.3 \mathrm{MPa})$ & $\mathrm{t}$ & 2763 \\
Steam $(<0.3 \mathrm{MPa})$ & $\mathrm{t}$ & 2303 \\
\hline
\end{tabular}

Process Energy Consumption of Raw Material Preparation (PEC $R M P$ )

The materials preparation stage includes two sub-stages: raw material extraction and transportation. The $P E C_{R M P}$ consists of process energy consumption of material preparation $\left(P E C_{M P}\right)$ and process energy consumption of material transportation $\left(P E C_{M T}\right)$ of unit urea production, as Equation (2).

$$
P E C_{R M P}=P E C_{M P}+P E C_{M T}
$$

where, the $E C_{M P}$ and $E C_{M T}$ can be determined by Equations (3) and (4), respectively.

$$
\begin{gathered}
P E C_{M P}=\sum R M_{x} \times E C_{x, i} \\
P E C_{M T}=\sum E I_{x, i, y} \times L_{x} \times R M_{x}
\end{gathered}
$$

where $x$ presents raw material coal; $y$ represents the transportation mode; $i$ represents the process energy; $P E C_{x, i}$ represents the EC of coal extraction by using process energy $i$, based on The Norm of 
The Energy Consumption Per Unit Production of Coal Underground Mining GB29444-2012 [46], with $\mathrm{EC}_{\mathrm{Coal} \text {, electrical }}$ set as $345.65 \mathrm{MJ} / \mathrm{t} ; L_{x}$ represents the transport distance of raw material $x(\mathrm{~km})$; and $E I_{x, i, y}$ represents the energy intensity by process energy $i$ in mode $y(\mathrm{MJ} / \mathrm{t} \cdot \mathrm{km})$, and the energy intensity of transportation mode refer to the literature $[32,47,48]$.

\subsection{GHG Emissions from $L c E C$}

The LCA is an essential tool for assessing the environmental impact in material, products, process, and service [31,49]. It is widely recognized as a quantitative evaluation method of environmental load internationally [50]. Based on global-warming potential (GWP) [51], the GHGs $\left(\mathrm{CO}_{2}, \mathrm{CH}_{4}, \mathrm{~N}_{2} \mathrm{O}\right)$ generated from the PEC in each sub-stage $f$ are determined by Equations (5)-(6).

$$
\begin{gathered}
G H G_{p}=\sum_{f} \sum_{i} \operatorname{PEC}_{f, i} \times E F_{f, i, p} \\
L c G H G=\sum G H G_{\mathrm{CO}_{2}}+25 \sum G H G_{\mathrm{CH}_{4}}+298 \sum G H G_{\mathrm{N}_{2} \mathrm{O}}
\end{gathered}
$$

where $P E C_{f, i}$ represents the consumption of process energy $i$ in sub-stage $f$, and $E F_{f, i, p}$ represents the emission factor of gas $p$ by process energy $i$ in the sub-stage $f, p \in\left\{\mathrm{CO}_{2}, \mathrm{CH}_{4}, \mathrm{~N}_{2} \mathrm{O}\right\}$.

The $E F$ consists of direct emission and indirect emission factors [32,43]. In this study, the direct emission factor relates to the exhaust gas produced by process energy use and combustion, whereas the indirect emission factor caused by the $\operatorname{LcEC}[43,44,52]$. Based on the literature $[32,42,43,53]$, the emission factors are demonstrated in Table 3.

\begin{tabular}{|c|c|c|c|c|c|c|c|}
\hline \multirow{2}{*}{ Classes } & \multirow{2}{*}{ Energy Type } & \multicolumn{3}{|c|}{ Direct Emission Factors } & \multicolumn{3}{|c|}{ Indirect Emission Factors } \\
\hline & & $\mathrm{CO}_{2}(\mathrm{~g} / \mathrm{MJ})$ & $\mathrm{CH}_{4}(\mathrm{~g} / \mathrm{MJ})$ & $\mathrm{N}_{2} \mathrm{O}(\mathrm{mg} / \mathrm{MJ})$ & $\mathrm{CO}_{2}(\mathrm{~g} / \mathrm{MJ})$ & $\mathrm{CH}_{4}(\mathrm{~g} / \mathrm{MJ})$ & $\mathrm{N}_{2} \mathrm{O}(\mathrm{mg} / \mathrm{MJ})$ \\
\hline \multirow{3}{*}{ Industrial } & Coal & 81.6 & 0.001 & 0.001 & 5.73 & 0.43 & 0.17 \\
\hline & Electricity & 0 & 0 & 0 & 248 & 2.16 & 0.62 \\
\hline & Steam & 0 & 0 & 0 & 114 & 0.29 & 1.79 \\
\hline \multirow{2}{*}{ Highway } & Gasoline & 67.9 & 0.08 & 0.002 & 28.8 & 0.09 & 0.47 \\
\hline & Diesel & 72.6 & 0.004 & 0.028 & 27.9 & 0.08 & 0.44 \\
\hline Railway & Diesel & 72.6 & 0.004 & 0.028 & 27.9 & 0.08 & 0.44 \\
\hline
\end{tabular}

Table 3. Direct and indirect emission factors of energy used $[32,42,43,53]$.

\subsection{Inventory Data}

In this study, the PEC data of each stage is gathered from 7 different urea plants, referred to as A, B, C, D, E, F, G, and H, respectively. Table 4 shows the distances and mode of raw material transportation. The process energy from the energy-consumed medium measured $\mathrm{RM}_{\text {coal }}$ (e.g., circulating water, condensate, etc.). Table 5 summarizes the PEC data of the synthesis stage and the waste-treatment stage. The specific information about the 7 urea plants are shown in Table 6. 
Table 4. The inventory data of process energy used in the materials preparation stage.

\begin{tabular}{ccccccc}
\hline Objects & Transportation & Energy & $\mathbf{R M}_{\text {coal }}$ (t/t Urea) & EC Coal,electrical $_{\text {[46] }}$ & Distances (km) & Energy Intensity (MJ/t km) [32,48] \\
\hline A & Highway & Gasoline & 0.68 & & 30 & 2.58 \\
B & Railway & Diesel & 0.62 & & 650 & 30 \\
C & Highway & Gasoline & 0.85 & $345.65 \mathrm{MJ} / \mathbf{t}$ & 30 & 2.58 \\
D & Railway & Diesel & 0.98 & & 30 & 0.11 \\
E & Highway & Diesel & 0.78 & & 760 & 2.35 \\
F & Railway & Diesel & 0.66 & 500 & 0.11 \\
G & Railway & Diesel & 1.04 & & & 0.11 \\
\hline
\end{tabular}

Table 5. The inventory data of process energy used in the synthesis stage and waste-treatment stage (MJ/t urea).

\begin{tabular}{|c|c|c|c|c|c|c|c|c|}
\hline \multirow{3}{*}{ Items } & \multicolumn{3}{|c|}{ Synthesis Stage } & \multirow{3}{*}{ Total } & \multicolumn{3}{|c|}{ Waste-Treatment Stage } & \multirow{3}{*}{ Total } \\
\hline & & & & & \multirow{2}{*}{$\begin{array}{c}\text { Exhaust Gas } \\
\text { Coal }\end{array}$} & \multirow{2}{*}{$\begin{array}{c}\text { Wastewater } \\
\text { Coal }\end{array}$} & \multirow{2}{*}{$\begin{array}{c}\text { Solid Waste } \\
\text { Coal }\end{array}$} & \\
\hline & Electricity & Steam & $\mathbf{R M}_{\text {coal }}$ & & & & & \\
\hline A & 1120 & 9630 & 2100 & 12,850 & 2210 & 16.7 & 5.22 & 2231.92 \\
\hline $\mathrm{B}$ & 3200 & 6520 & 961 & 10,681 & 2240 & 21.3 & 3.73 & 2265.03 \\
\hline $\mathrm{C}$ & 353 & 12,080 & 1540 & 13,973 & 6430 & 14.8 & 6.71 & 6451.51 \\
\hline $\mathrm{D}$ & 2980 & 9180 & 1360 & 13,520 & 1180 & 6.65 & 24.2 & 1210.85 \\
\hline $\mathrm{E}$ & 1210 & 16,300 & 21,500 & 39,010 & 6760 & 6.06 & 8.94 & 6775 \\
\hline $\mathrm{F}$ & 585 & 10,300 & 2130 & 13,015 & 5206 & 102 & 18.3 & 5326.3 \\
\hline $\mathrm{G}$ & 360 & 13,400 & 873 & 14,633 & 5130 & 16.8 & 9.31 & 5156.11 \\
\hline
\end{tabular}


Table 6. The specific information about 7 urea production processes.

\begin{tabular}{|c|c|c|c|c|c|c|}
\hline \multirow{3}{*}{ Project } & \multicolumn{2}{|c|}{ Materials Preparation Stage } & \multicolumn{3}{|c|}{ Synthesis Stage } & \multirow{3}{*}{ Urea quality } \\
\hline & \multirow{2}{*}{ Raw Materials } & \multirow{2}{*}{ Transport } & Ammonia Synthesis & \multicolumn{2}{|c|}{ Urea Synthesis } & \\
\hline & & & Gasification Technology & Process & Equipment & \\
\hline A & Coal & Highway & $\begin{array}{l}\text { Hangtian pulverized coal pressure } \\
\text { gasification technology (HT-L) }\end{array}$ & $\mathrm{CO}_{2}$ stripping & Fluid bed big granular urea unit (Hydro) & $\mathrm{TN} \geq 46.5$ \\
\hline B & Coal & Railway & Continuously gasification & The improved water cycle process & Modified water cycle urea plant & $\mathrm{TN} \geq 46.4$ \\
\hline C & Coal & Highway & Shell coal gasification process & Improved $\mathrm{CO}_{2}$ stripping & Modified $\mathrm{CO}_{2}$ stripping method urea plant & $\mathrm{TN} \geq 46.4$ \\
\hline $\mathrm{D}$ & Coal & Railway & Intermittent fixed-bed gasification & Water cycle process & Water cycle urea plant & $\mathrm{TN} \geq 46.3$ \\
\hline $\mathrm{E}$ & Coal & Highway & Intermittent fixed-bed gasification & $\mathrm{CO}_{2}$ stripping & $\mathrm{CO}_{2}$ stripping method urea plant & $\mathrm{TN} \geq 46.2$ \\
\hline $\mathrm{F}$ & Coal & Railway & Continuous coal gasification & New $\mathrm{CO}_{2}$ stripping & $\mathrm{CO}_{2}$ stripping method urea plant & $\mathrm{TN} \geq 46.4$ \\
\hline G & Coal & Highway & Pulverized coal pressure gasification process & $\mathrm{CO}_{2}$ stripping & $\mathrm{CO}_{2}$ stripping method urea plant & $\mathrm{TN} \geq 46.3$ \\
\hline
\end{tabular}




\section{Results and Discussion}

\section{1. $L c E C$}

The LcEC of 7 urea plants was calculated by Equations (1)-(4) using data in Tables 1, 5 and 6. As shown in Figure 2, the LcEC of the 7 industry operations is $22.5 \mathrm{GJ} / \mathrm{t}$ urea, 23.6 GJ/t urea, 26.1 GJ/t urea, 25.9 GJ/t urea, 60.0 GJ/t urea, 25.3 GJ/t urea, 27.4 GJ/t urea, respectively. Because of the significant $\mathrm{EC}_{\mathrm{pp}}$, industry E presented the highest EC. However, since the production equipment in the urea industry has different service life and different loss degree, this study focuses on the comparison of the EC and GHG emissions in different stages of urea production. The purpose of collecting and evaluating the EC of 7 urea plants is to demonstrate the commonality of EC characteristics in the life cycle of urea production. Therefore, according to Figure 2, the life cycle performance of urea EC presented a significant EC in the synthesis stage and the lowest EC in the material preparation stage, where the average $\mathrm{EC}_{\mathrm{RMP}}, \mathrm{EC}_{\mathrm{PP}}, \mathrm{EC}_{\mathrm{WD}}$ accounted for $1.3 \%, 82.4 \%$, and $16.3 \%$ of $\mathrm{LcEC}$, respectively.

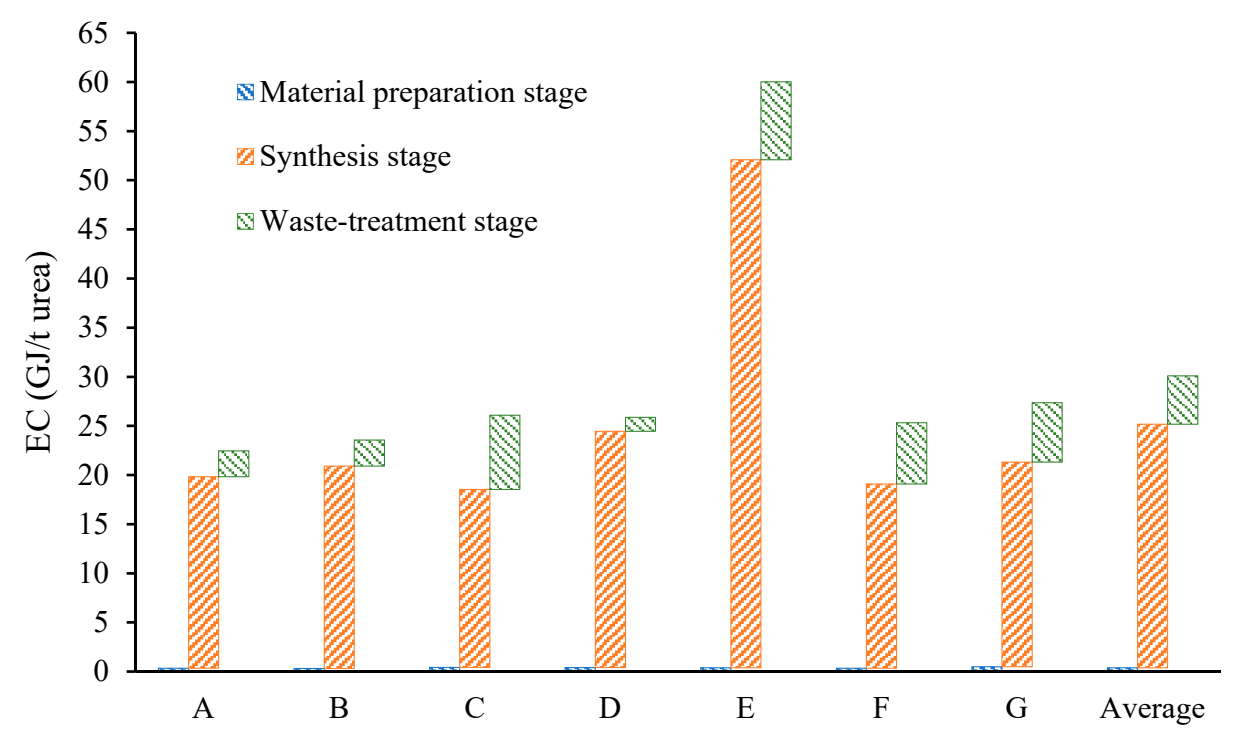

Figure 2. Distribution of life cycle of energy consumption (LcEC) by stages from 7 urea industries.

In order to reveal the dominant primary fossil energy in the life cycle of urea production, the primary fossil energy consumption was analyzed and is shown in Figure 3. It presents that coal is the dominating energy inputs of the urea industry, accounting for $94.4 \%$ of LcEC. In contrast, oil and NG are a tiny fraction of LcEC, accounting for $0.144 \%$ and $5.42 \%$ of LcEC, respectively. According to the China Statistical Yearbook 2019, coal is the primary source of energy in China; coal, oil, NG, primary electricity, and other energy sources account for 59.0\%, 18.9\%, 7.8\%, and 14.3\% of total EC in 2019, respectively [54]. Thus, the proportion of coal consumption of the urea industry is higher than that of coal in the whole country. Driven by resource and environmental constraints, as well as pressure to reduce GHG emissions, China's primary energy consumption structure is expected to shift in the coming decades [55]. Reducing coal consumption in the urea industry is an effective way to help achieve this goal. 


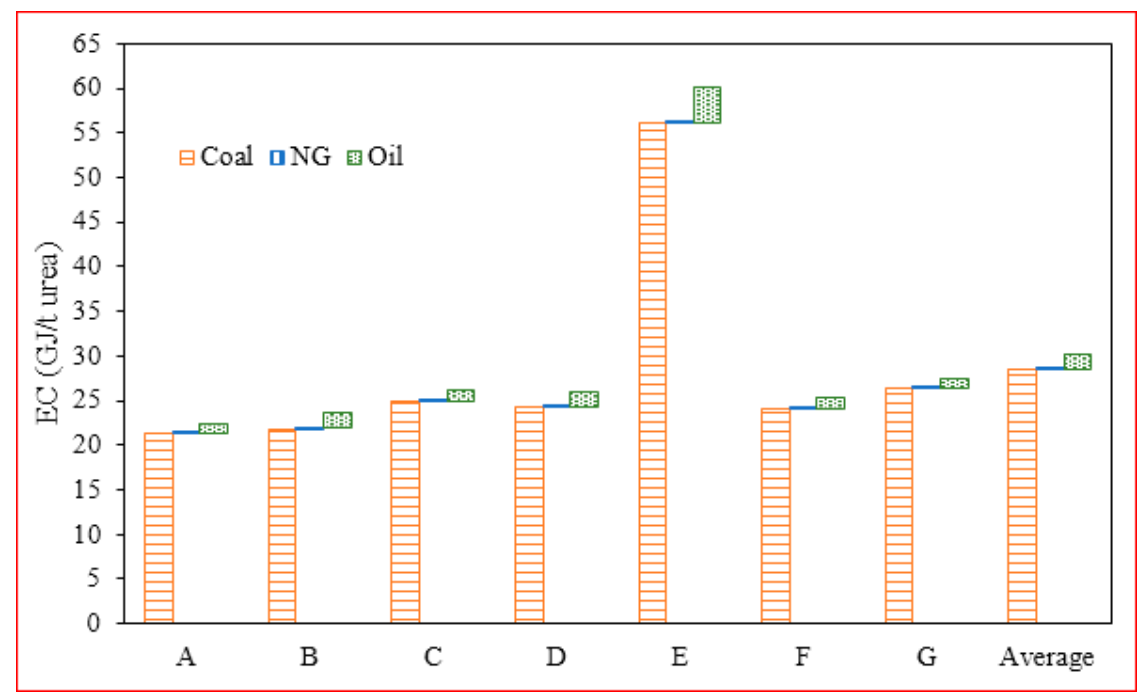

Figure 3. Distribution of LcEC for urea production.

Based on the analysis of the average LcEC of 7 urea industries, the distribution of primary fossil energy consumption by stage is shown in Figure 4. The results suggest that the average LcEC is about $30.1 \mathrm{GJ} / \mathrm{t}$ urea, where the materials preparation stage, synthesis stage, and waste-treatment stage consuming about $0.388 \mathrm{GJ} / \mathrm{t}$ urea, $24.8 \mathrm{GJ} / \mathrm{t}$ urea, and $4.92 \mathrm{GJ} / \mathrm{t}$ urea of energy, respectively. As mentioned before (Figure 3), coal is the dominant primary fossil fuel energy in the life cycle of urea production. Figure 4 reveals that in the life cycle of urea production, about $1.06 \%$ of coal is consumed by the material preparation stage, $83.3 \%$ of coal is used in the synthesis stage, and $15.7 \%$ of coal is consumed in the waste-treatment stage. Additionally, the consumption of coal in the material preparation stage, the synthesis stage, and the waste-treatment stage account for about $77.9 \%, 95.5 \%$, and $90.6 \%$ of the total energy consumed in each stage, respectively. Undoubtedly, the synthesis stage is an energy-intensive stage in the life cycle of the urea production process. An in-depth analysis of the EC performance of the synthesis stage helps provides a robust scientific basis for adjusting EC in the urea industry, as shown in Figure 5.

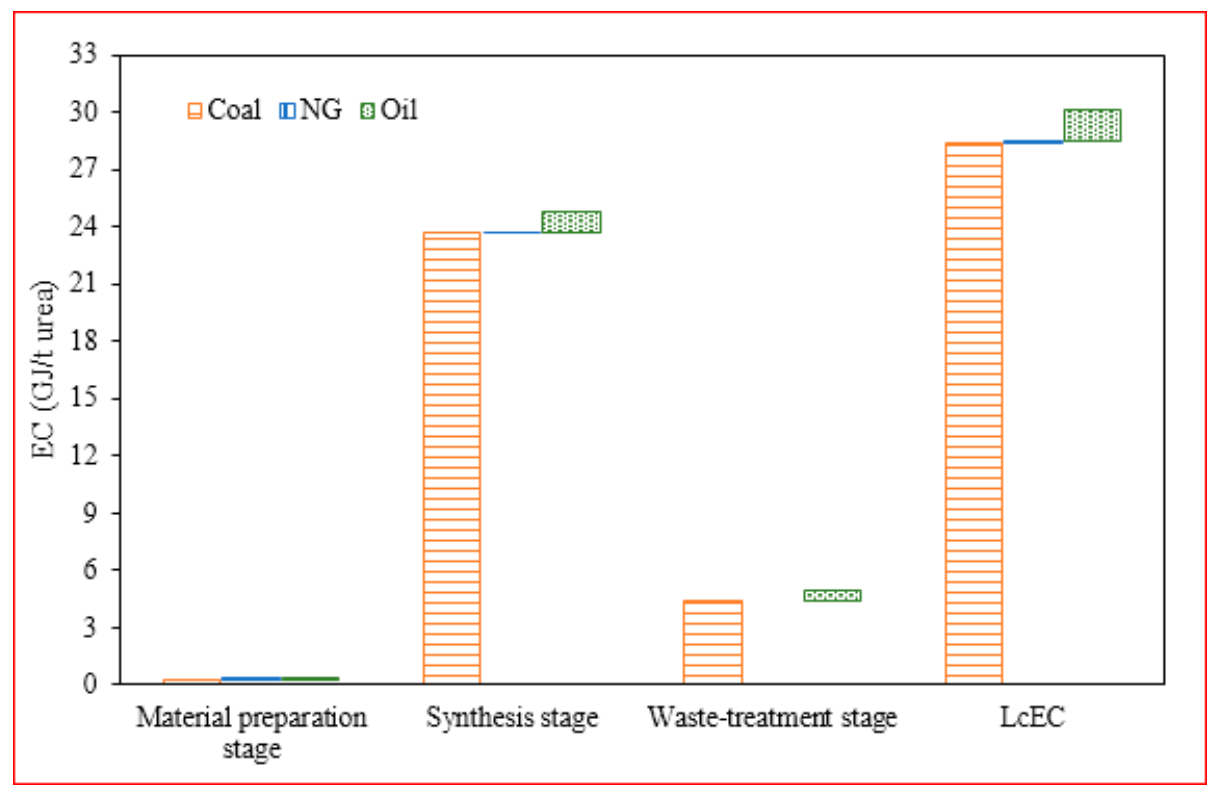

Figure 4. Distribution of average primary fossil energy consumption by stages. 


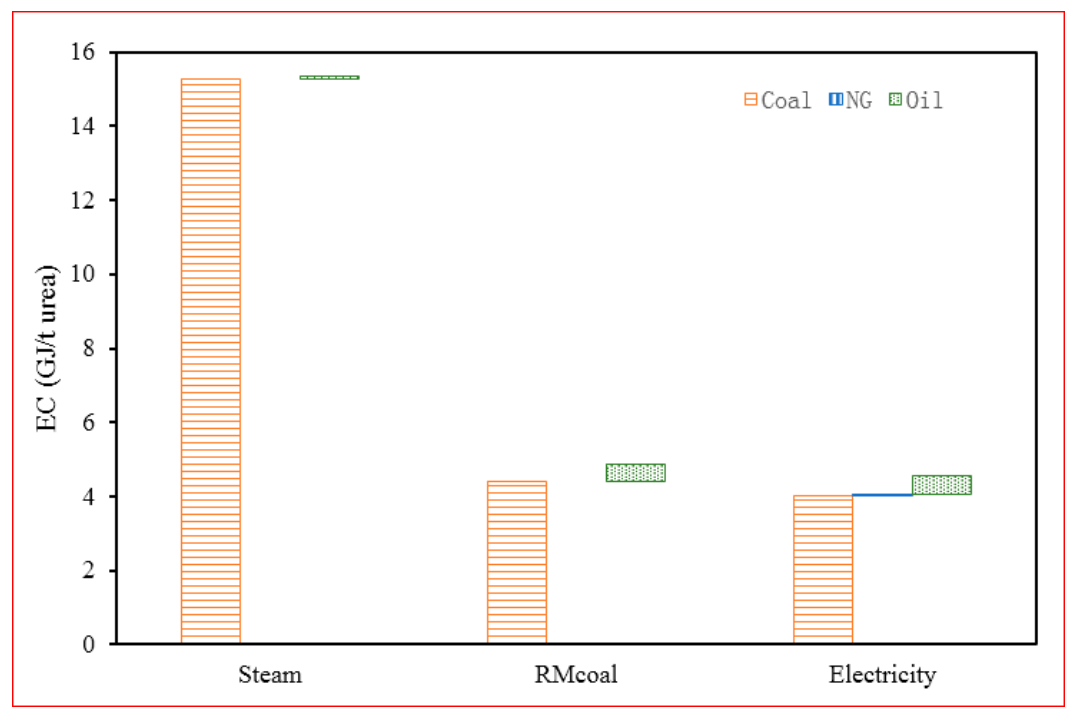

Figure 5. Distribution of average primary fossil energy consumption by the process energy used in the synthesis stage.

In the synthesis stage, the distribution of average primary fossil energy consumption by process energy used is shown in Figure 5. The results reveal that in the synthesis stage, steam is the dominating source of primary fossil energy consumption, which accounts for about $62.0 \%$ of $\mathrm{EC}_{\mathrm{PP}}$. Besides, coal plays a vital role in the generation of process energy. Based on Figures 4 and 5, 95.5\% of process energy in the synthesis stage is supported by coal, where $15.3 \mathrm{GJ} / \mathrm{t}$ urea of coal is used to support steam generation, about $4.40 \mathrm{GJ} / \mathrm{t}$ urea of coal is used to support the $\mathrm{RM}_{\text {coal }}$ consumption (which replaces the process energy used by energy-used mediums), and about $4.01 \mathrm{GJ} / \mathrm{t}$ urea of coal is used to support the electricity. In other words, nearly $99.3 \%, 90.6 \%$, and $87.7 \%$ of steam, $\mathrm{RM}_{\text {coal }}$, and electricity come from coal consumption, respectively. The proportion of coal consumption in the generation of process energy in the synthesis stage is significantly higher than that of coal in the whole country. Thus, how to decline steam consumption or use clean energy instead is a question worth considering in the transformation of the urea industry. According to the study of LcEC performance of urea production, there is an urge to transform the industrial energy mix, including the improvement of energy efficiency in energy-intensive processes and the use of clean energy to accelerate the transformation of China's energy structure and improve energy security.

\section{2. $L c G H G s$}

Based on Tables 2-5, the LcGHGs is calculated by Equations (5) and (6). The results shown in Figure 6 suggest that the 7 urea industries generate $2.01 \mathrm{t}$ eq. $\mathrm{CO}_{2} / \mathrm{t}$ urea, $2.15 \mathrm{t}$ eq. $\mathrm{CO}_{2} / \mathrm{t}$ urea, $2.32 \mathrm{t}$ eq. $\mathrm{CO}_{2} / \mathrm{t}$ urea, $2.37 \mathrm{t}$ eq. $\mathrm{CO}_{2} / \mathrm{t}$ urea, $5.21 \mathrm{t}$ eq. $\mathrm{CO}_{2} / \mathrm{t}$ urea, $2.24 \mathrm{t}$ eq. $\mathrm{CO}_{2} / \mathrm{t}$ urea, and $2.45 \mathrm{t}$ eq. $\mathrm{CO}_{2} / \mathrm{t}$ urea of LcGHGs by consuming energy, respectively. The average LcGHGs is about $2.68 \mathrm{t}$ eq. $\mathrm{CO}_{2} / \mathrm{t}$ urea. The distribution of GHG emissions by stage presents a similar trend with EC in urea production (Figure 2). In the life cycle of urea production, the GHG emissions generated by EC in the synthesis stage are significantly larger than that in the other stage, with an average of about $2.18 \mathrm{t}$ eq. $\mathrm{CO}_{2} / \mathrm{t}$ urea, accounting for $81.3 \%$ of the LcGHG emissions. The emission of GHGs in the material preparation stage and waste-treatment stage is about $0.09 \mathrm{t}$ eq. $\mathrm{CO}_{2} / \mathrm{t}$ urea and $0.41 \mathrm{t}$ eq. $\mathrm{CO}_{2} / \mathrm{t}$ urea which accounts for $3.31 \%$ and $15.4 \%$ of LcGHGs, respectively. Therefore, the synthesis stage is not merely a stage with intensive EC, but also a step with high-intensity GHG emissions. This phenomenon in line with the fact that EC is proportional to GHG emissions. 


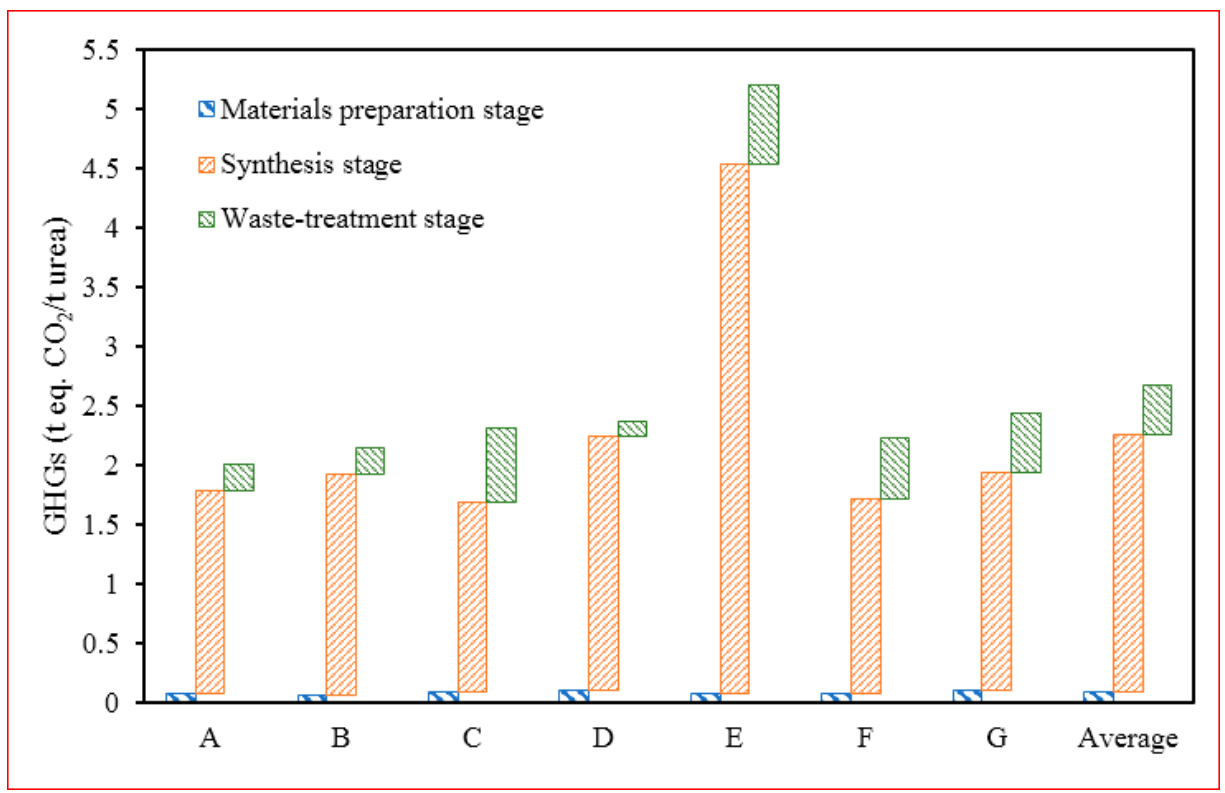

Figure 6. The life cycle of GHG (LcGHG) emissions from 7 urea industries.

The distribution of LcGHG emissions, shown in Figure 7, reveals that $\mathrm{CO}_{2}$ is the dominant GHGs emission, accounting for $90.0 \%$ of LcGHG emissions, followed by $\mathrm{CH}_{4} \cdot \mathrm{N}_{2} \mathrm{O}$ is negligible for the GHG emissions of the LcEC. In detail, the $\mathrm{CO}_{2}$ equivalent emission is $2.41 \mathrm{t}$ eq. $\mathrm{CO}_{2} / \mathrm{t}$ urea, in which $81.7 \%$ is from the synthesis stage, $15.2 \%$ comes from the waste-treatment stage, and $3.05 \%$ comes from the material preparation stage. $\mathrm{CO}_{2}$ equivalent emissions of the material preparation stage, synthesis stage, and waste-treatment stage account for $82.9 \%, 90.5 \%$, and $89.0 \%$ of GHG emissions, and the corresponding $\mathrm{CH}_{4}$ equivalent emissions account for $17.0 \%, 9.22 \%$, and $11.0 \%$ of GHG emissions, respectively. The distribution of LcGHG in Figure 7 presents a similar trend with LcEC in Figure 4. Coal is the primary source of $\mathrm{CO}_{2}$ emission. A great deal of coal consumption in each stage is responsible for the emission of high $\mathrm{CO}_{2}$ concentration. Therefore, reducing coal's share in EC is the most direct way to reduce GHG emissions in the urea plant.

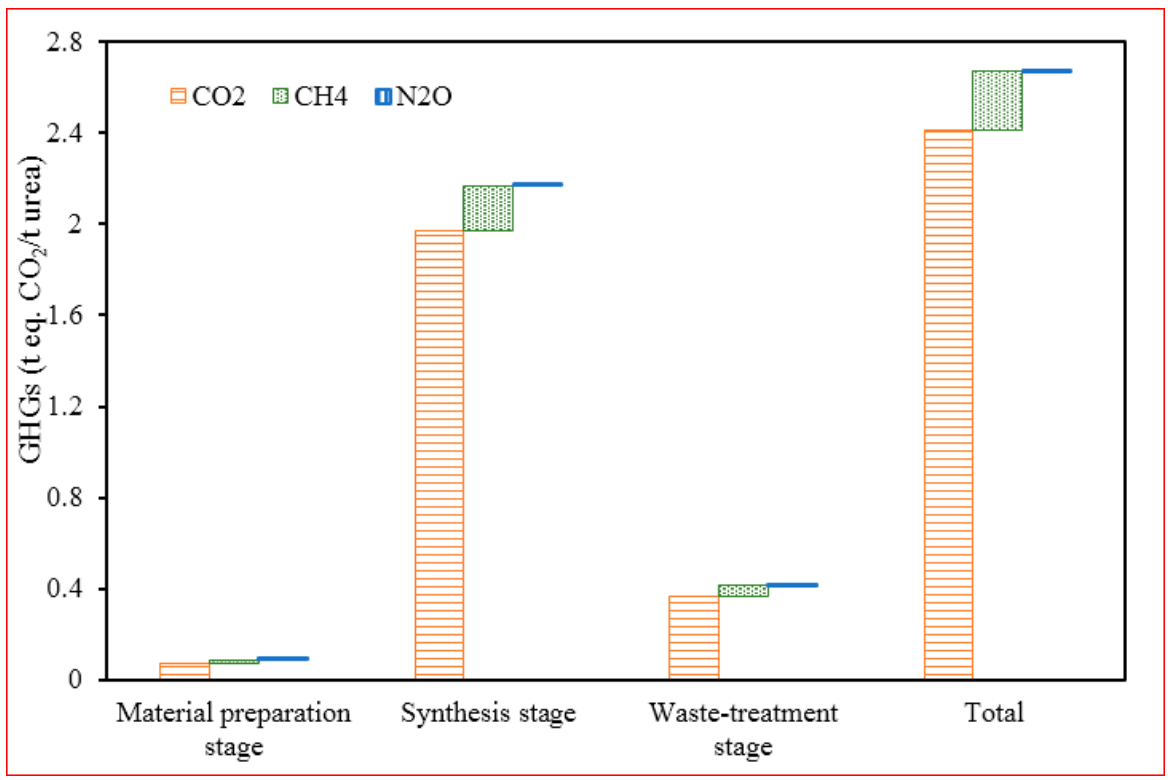

Figure 7. Distribution of LcGHG emissions. 
Figure 8 shows the GHG emissions from different process energy inputs in the synthesis stage. The consumption of electricity, steam, and $\mathrm{RM}_{\text {coal }}$ produces GHGs of about $0.42 \mathrm{t}$ eq. $\mathrm{CO}_{2} / \mathrm{t}$ urea, $1.35 \mathrm{t}$ eq. $\mathrm{CO}_{2} / \mathrm{t}$ urea, and $0.41 \mathrm{t}$ eq. $\mathrm{CO}_{2} / \mathrm{t}$ urea, respectively. The GHGs produced by steam consumption account for $61.8 .0 \%$ of the total GHG emissions in the synthesis stage. From the perspective of distribution, the generation of $\mathrm{CO}_{2}$ equivalent emissions by electricity, steam, and $\mathrm{RM}_{\text {coal }}$ consumption account for $82.1 \%, 93.6 \%$, and $89.0 \%$ of GHG emissions, and the corresponding $\mathrm{CH}_{4}$ equivalent emissions account for $17.9 \%, 5.96 \%$, and $11.0 \%$, respectively. Therefore, steam is the main reason for GHG emissions with high $\mathrm{CO}_{2}$ concentration. As shown in Figure 5 and Table 5, steam consumes about $15.3 \mathrm{GJ} / \mathrm{t}$ urea of coal, and accounts for over $64 \%$ of total coal consumption (23.7 GJ/t urea). The relatively higher proportion of coal consumed may be responsible for the higher $\mathrm{CO}_{2}$ content of the GHGs during the synthesis stage. Thus, combined with the result from Figure 5, it is useful to replace coal with green energy or to increase the energy efficiency of steam-consuming substage in the synthesis stage in order to reduce EC and GHG emissions in the life cycle of urea production.

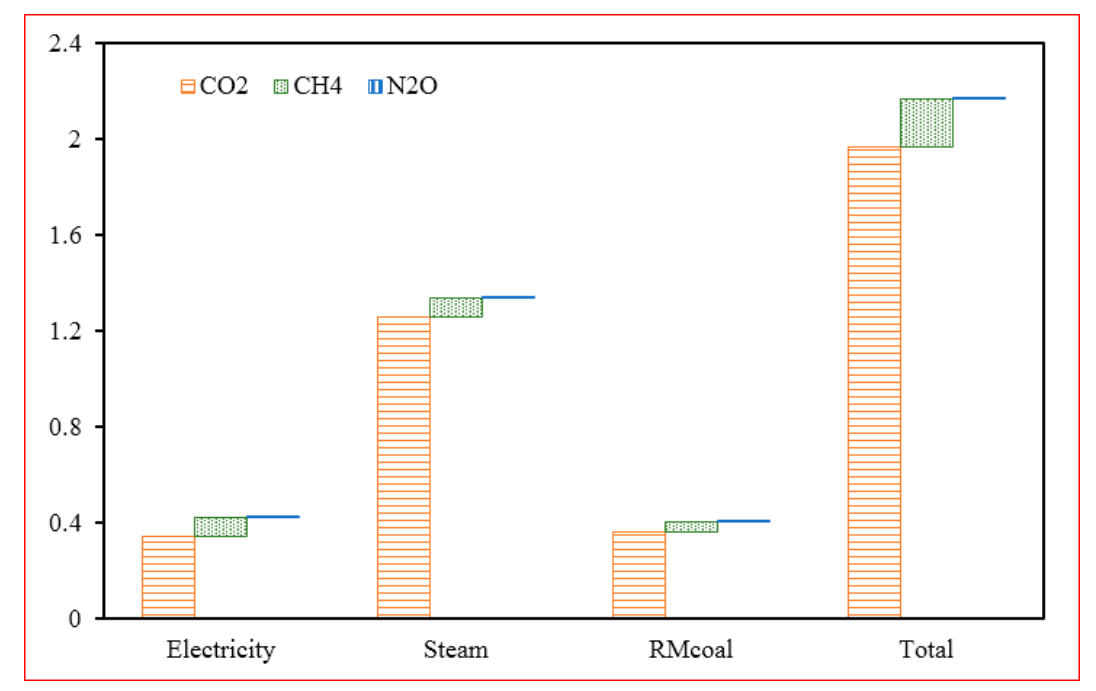

Figure 8. Distribution of GHG emissions by process energy used in the synthesis stage.

\subsection{Implications of the Results}

The LcEC analysis illustrates the following: (1) The synthesis stage is the leading energy-consuming stage in life cycle urea production, accounting for $82.4 \%$ of LcEC. Steam, electricity, and $\mathrm{RM}_{\text {coal }}$ are the primary process energies used in the synthesis stage. The supply of steam consumes $62.0 \%$ of $\mathrm{EC}_{\mathrm{pp}}$. The steam-consuming equipment is responsible for the high $\mathrm{EC}$ of urea production. (2) Coal is the dominant primary fossil energy in each stage, accounting for $94.4 \%$ of LcEC. Based on the China Statistical Yearbook 2019, coal accounts for 59.0\% of the total primary energy consumption in China [54]. The proportion of coal consumption in the urea industry is higher than that of coal consumption generally in China. Therefore, the urea industry has excellent potential for coal energy-saving. Besides, improving the energy efficiency of steam-consuming equipment or replacing coal with green energy is an effective way to reduce coal consumption in the urea industry.

GHG emissions are closely related to the amount of energy used and the type of energy consumed. Due to the life cycle performance of EC in the urea industry, LcGHG emissions present a similar trend with LcEC. In detail, $\mathrm{CO}_{2}$ equivalent emissions of the material preparation stage, synthesis stage, and waste-treatment stage account for $82.9 \%, 90.5 \%$, and $89.0 \%$ of GHG emissions of each stage. Coal is the primary source of $\mathrm{CO}_{2}$ emission. As shown in Figure 4, the higher proportion of coal consumed during the synthesis stage may be responsible for the higher $\mathrm{CO}_{2}$ content of the GHGs during this phase. Applying renewable energies, such as low-carbon and renewable biomass provided by biorefinery [56], is critical toward a more sustainable energy system $[57,58]$. Therefore, the utilization of renewable energy is the right approach to change the situation of high GHG emissions. 


\section{Conclusions}

In this study, the LCA is applied to establish a life cycle framework of urea production, which divides the life cycle into three stages: the material preparation stage, synthesis stage, and waste-treatment stage. Based on the inventory data onto 7 real urea industries, LcEC of urea production, and LcGHG emissions generated by the process of EC are studied in this paper. The results show that the average $\mathrm{LcEC}$ is about $30.1 \mathrm{GJ} / \mathrm{t}$ urea. The $\mathrm{EC}_{\mathrm{RMP}}, \mathrm{EC}_{\mathrm{PP}}$, and $\mathrm{EC}_{\mathrm{WD}}$ is about $0.388 \mathrm{GJ} / \mathrm{t}$ urea, $24.8 \mathrm{GJ} / \mathrm{t}$ urea, and $4.92 \mathrm{GJ} / \mathrm{t}$ urea, accounting for $1.3 \%, 82.4 \%$, and $16.3 \%$ of average LcEC, respectively (Figure 2). Coal plays the primary energy in the urea production, which supports $94.4 \%$ of $\mathrm{LcEC}$ (Figure 3), and $77.9 \%$ of $\mathrm{EC}_{\mathrm{RMP}}, 95.5 \%$ of $\mathrm{EC}_{\mathrm{PP}}$, and $90.6 \%$ of $\mathrm{EC}_{\mathrm{WD}}$ (Figure 4 ). Therefore, the synthesis stage is the dominant energy consumer, in which the supplying of steam consumes $62.0 \%$ of $\mathrm{EC}_{\mathrm{pp}}$, where $99.3 \%$ comes from coal consumption (Figure 5). It reveals that the proportion of coal consumption in the life cycle of the urea industry is higher than that of coal consumption generally in China. Besides, due to the life cycle performance of EC in the urea industry, LcGHG emissions present a similar trend with $\mathrm{LcEC}$ (Figure 6). In detail, $\mathrm{CO}_{2}$ equivalent emissions of the material preparation stage, synthesis stage, and waste-treatment stage account for $82.9 \%, 90.5 \%$, and $89.0 \%$ of GHG emissions of each stage (Figure 7). Finally, the steam-consuming produces $1.35 \mathrm{t}$ eq.CO $\mathrm{CO}_{2} / \mathrm{t}$ urea GHG emissions, accounting for $61.8 \%$ of the total GHG emissions from the synthesis stage; in detail, the generation of $\mathrm{CO}_{2}$ equivalent emissions by steam account for $93.6 \%$ of GHG emissions (Figure 8).

Urea production technologies and processes have been widely studied, and the results have been visible progress. The performance of EC and GHG emissions in the life cycle of urea production illustrates that whatever process or technique used in the urea factory nowadays, the reduction of coal consumption will still be a crucial task for the urea industry. Improving the energy efficiency of steam-consuming equipment or replacing coal with green energy is an effective way to reduce coal consumption. Besides, the promotion of the application of green energy, such as renewable energy, will contribute to the reform of industrial energy consumption structure, reduce the consumption of primary energy, and relieve GHG emissions. This is a powerful driving force for the realization of sustainable industrial development in the future.

Author Contributions: The research conceptualization and methodology were conceived and designed by L.S., L.L., B.Y., and T.X.; data was collected and analyzed by L.S., L.L., and B.Y.; the paper was written by L.S., L.L., B.Y., and G.S.; and the manuscript was revised by T.X. All authors have read and agreed to the published version of the manuscript.

Funding: This research was funded by the National Key Research and Development Program of China (2018YFC0704703), the National Natural Science Foundation of China (71874174), the Pilot Project of Science and Technology Program of Fujian Province (2019Y0075) and the China Scholarship Council.

Acknowledgments: We would like to thank Deyu Li of the University of Cambridge for his suggestions and modifications.

Conflicts of Interest: The authors declare no conflict of interest.

\section{References}

1. United Nations. Climate Change. Available online: https://www.un.org/en/sections/issues-depth/climatechange/ (accessed on 5 April 2020).

2. EPA. Greenhouse Gas Emission. Available online: https://www.epa.gov/ghgemissions/sources-greenhousegas-emissions (accessed on 5 April 2020).

3. Wei, Y.M.; Liao, H. Relationship between energy efficiency and the economic system: Measuring energy efficiency. In Energy Economics: Energy Efficiency in China; Springer: Berlin/Heidelberg, Germany, 2016; pp. 53-80. ISBN 978-3-319-44631-8.

4. Fan, D. Research on Energy Efficiency in China from the Perspective of Low Carbon. Ph.D. Thesis, Dongbei University of Finance and Economics, Dalian, China, 2013. 
5. Fu, S.; Shailly, K.; Nishant, J.; Rinki, J. Energy Efficiency Policies in China and India. Available online: https: //www.teriin.org/files/energy-efficiency/files/downloads/China\%20India\%20EE\%20Paper.pdf. (accessed on 20 February 2020).

6. Malinauskaite, J.; Jouhara, H.; Ahmad, L.; Milani, M.; Montorsi, L.; Ventrurelli, M. Energy efficiency in industry: EU and National Policies in Italy and the UK. Energy 2019, 172, 255-269. [CrossRef]

7. Chen, Y.Y.; Wang, L.K. The impact of FDI on regional industrial energy efficiency: An empirical analyses on FDI source. Cn. Popul. Resour. Environ. 2010, 20, 28-33.

8. Industrial Energy Efficiency for Sustainable Wealth Creation Capturing Environmental, Economic and Social Dividends; Industrial Development Report 2011; UNIDO: Vienna, Austria, 2011.

9. Kassai, M.; Poleczky, L.; Al-Hyari, L.; Kajtar, L.; Nyers, J. Investigation of the energy recovery potentials in ventilation systems in different climates. Mech. Eng. 2018, 16, 203-217. [CrossRef]

10. Khan, A.R.; Al-Awadi, L.; Al-Rashidi, M.S. Control of ammonia and urea emissions from urea manufacturing facilities of petrochemical industries company (PIC), Kuwait. J. Air Waste Manag. Assoc. 2016, 66, 609-618. [CrossRef]

11. IEA. Tracking Industry. Available online: https://www.iea.org/reports/tracking-industry-2019 (accessed on 26 December 2019).

12. EIA. International Energy Outlook 2019 with Projections to 2050. Available online: https://www.eia.gov/ outlooks/ieo/pdf/ieo2019.pdf (accessed on 20 February 2020).

13. EIA. International Energy Outlook 2016. Available online: https://www.eia.gov/outlooks/ieo/pdf/0484(2016) .pdf (accessed on 17 September 2017).

14. Kassai, M.; Ge, G.; Simonson, C.J. Dehumidification performance investigation of run-around membrane energy exchanger system. Therm. Sci. 2016, 20, 1927-1938. [CrossRef]

15. Santos, P.C.; Szklo, A.S. Urea imports in Brazil: The increasing demand pressure from the biofuels industry and the role of domestic natural gas for the country's urea production growth. J. Nat. Gas Sci. Eng. 2016, 29, 188-200. [CrossRef]

16. EIA. China International Energy Data and Analysis. Available online: https://www.eia.gov/beta/international/ analysis_includes/countries_long/China/china.pdf (accessed on 15 January 2018).

17. BP Energy Outlook. Country and Regional Insights-China. Available online: https: //www.bp.com/content/dam/bp/en/corporate/pdf/energy-economics/energy-outlook/bp-energy-outlook2018-country-insight-china.pdf (accessed on 15 December 2018).

18. Facts \& Figures of the European Chemical Industry 2018. Available online: https://www.apquimica.pt/ uploads/fotos_artigos/files/cefic-facts-and-figures-2018-industrial.pdf (accessed on 2 December 2019).

19. Chemicals Industry Profiles World Chemicals Sales: Geographic Breakdown. Available online: http://www.rsc.org/learn-chemistry/resources/business-skills-and-commercial-awareness-forchemists/docs/businessdoc1.pdf (accessed on 8 October 2019).

20. Mo, H.B. Discussion on safety and economy of urea synthesis process. Chem. Eng. Des. Commun. 2012, 2, 60-62.

21. Top Urea Producing Countries. Available online: https://amootiranian.com/top-urea-producing-countries/ (accessed on 5 November 2019).

22. Urea Chemical Economics Handbook. Available online: https://ihsmarkit.com/products/urea-chemicaleconomics-handbook.html (accessed on 5 November 2019).

23. Muralikrishna, L.V.; Manickam, V. Life cycle assessment. In Environmental Management Science and Engineering for Industry; Butterworth-Heinemann: Oxford, UK, 2017; pp. 57-75. ISBN 978-0-12-811989-1.

24. Curran, M.A. Encyclopedia of Ecology, 2nd ed.; Fath, B., Ed.; Elsevier: Amsterdam, The Netherlands, 2016; Volume 4, pp. 359-366.

25. Wang, X.X. Policies on Industrial Energy Efficiency Utilization Promotion in Shanghai. Master's Thesis, Shanghai Jiao Tong University, Shanghai, China, 2014.

26. Wang, Q.; Zheng, Y.; Wu, S.D.; Li, T.T. Mechanism of energy efficiency response to industrial restructuring and energy consumption structure change. Acta. Geogr. Sin. 2011, 66, 741-749.

27. Li, H.; Shi, J.F. Energy efficiency analysis on Chinese industrial sectors: An improved super-sbm model with undesirable outputs. J. Clean. Prod. 2014, 65, 97-107. [CrossRef]

28. Tao, R. Research in Shanghai Energy Forecast Model and Energy Efficiency Evaluation Indicators System. Master's Thesis, Shanghai Jiao Tong University, Shanghai, China, 2012. 
29. Wu, Y.Y.; Li, Y. Energy efficiency of industrial sector's in Shandong province and its influencing factors. CN. Popul. Resour. Environ. 2015, 25, 114-120.

30. Tukker, T. Life cycle assessment as a tool in environmental impact assessment. Environ. Impact Assess. Rev. 2000, 20, 435-456. [CrossRef]

31. Brusseau, M.L. Sustainable development and other solutions to pollution and global change. In Environmental and Pollution Science, 3rd ed.; Brusseau, M.L., Pepper, I.L., Gerba, C.P., Eds.; Academic Press: Amsterdam, The Netherlands, 2019; pp. 585-603.

32. Xiang, D.; Yang, S.Y.; Li, X.X.; Qian, Y. Life cycle assessment of energy consumption and GHG emissions of olefins production from alternative resources in China. Energy Convers. Manag. 2015, 90, 12-20. [CrossRef]

33. Costa, T.P.D.; Westphalen, G.; Nora, F.B.D.; Silva, B.D.Z.; Rosa, G.S.D. Technical and environmental assessment of coated urea production with a natural polymeric suspension in spouted bed to reduce nitrogen losses. J. Clean. Prod. 2019, 222, 324-334. [CrossRef]

34. Panjeshahi, M.H.; Langeroudi, G.E.; Tahouni, N. Retrofit of ammonia plant from improving energy efficiency. Energy 2008, 33, 46-64. [CrossRef]

35. Kirova-Yordanova, Z. Exergy-based estimation and comparison of urea and ammonium nitrate production efficiency and environmental impact. Energy 2017, 140, 158-169. [CrossRef]

36. Rollinson, A.N.; Jones, J.; Dupont, V.; Twigg, M.V. Urea as a hydrogen carrier: A perspective on its potential for safe, sustainable and long-term energy supply. Energy Environ. Sci. 2011, 4, 1216. [CrossRef]

37. Guo, J.M. Conversion rate of urea synthesis process and enhance research. Guangdong Chem. Ind. 2013, 15, 104-111.

38. Copplestone, J.C.; Kirk, C.M.; Death, S.L.; Betteridge, N.G.; Kirk, C.M. Ammonia and Urea Production. Available online: https://nzic.org.nz/app/uploads/2017/10/1A.pdf (accessed on 28 April 2020).

39. Kumar, B. Manufacture of Urea. Bachelor of Technology in Chemical Engineering Thesis, National Institute of Technology Rourkela, Rourkela, India, May 2007. B.Tech.

40. International Organization for Standardization. Environmental Management_Life Cycle Assessment: Principle and Framework. Management Environment-Exigences; ISO 14040; ISO: Geneva, Switzerland, 2006.

41. International Organization for Standardization. Environmental Management-Life Cycle Assessment Requirements and Guidelines. Management Environmental-Principes; ISO 14044; ISO: Geneva, Switzerland, 2006.

42. Brynolf, S.; Fridell, E.; Andersson, K. Environmental assessment of marine fuels: Liquefied natural gas, liquefied biogas, methanol and bio-methanol. J. Clean. Prod. 2014, 74, 86-95. [CrossRef]

43. Ou, X.M.; Yan, X.Y.; Zhang, X.L. Life-cycle energy consumption and greenhouse gas emissions for electricity generation and supply in China. Appl. Energy 2011, 88, 289-297. [CrossRef]

44. Li, G.X.; Cui, P.Z.; Wang, Y.L.; Liu, Z.Q.; Zhu, Z.Y.; Yang, S. Life cycle energy consumption and GHG emission of biomass-to-hydrogen process in comparison with coal-to-hydrogen process. Energy 2010, 191, 116588. [CrossRef]

45. Energy Consumption Quota for Oil Refining Industry. DB37/754-2007. Available online: http://www.syhgjn. cn/news/view/7083-1.html (accessed on 15 February 2020).

46. The Norm of The Energy Consumption Per Unit Production of Coal Underground Mining. GB29444-2012. Available online: http://openstd.samr.gov.cn/bzgk/gb/newGbInfo?hcno= F2264FE27AD4688868A72C4DD87F77B0 (accessed on 26 January 2020).

47. Energy Statistical Reporting System (2018-2019). Available online: http://tjj.shanxi.gov.cn/tjzs/tjzd/201903/ t20190314_99491.shtml (accessed on 15 February 2020).

48. Liu, D. Cargo Transportation Structure Optimization Research Based on Energy Consumption. Master's Thesis, Beijing Jiaotong University, Beijing, China, 2014.

49. Li, S.H. Life Cycle Assessment and Environmental Benefits Analysis of Electric Vehicles. Ph.D. Thesis, Jilin University, Changchun, China, 2014.

50. Feng, C.; Xu, Z.Q. Research on the development of medium and long term private electric vehicles for large-scale development of conventional air pollutants. Energy China 2016, 38, 40-44.

51. Intergovernmental Panel on Climate Change. IPCC Fourth Assessment Report: Climate Change 2007; IPCC: Cambridge, UK, 2007.

52. Zhao, Z.T.; Liu, Y.; Wang, F.; Li, X.K.; Deng, S.P.; Xu, J. Life cycle assessment of primary energy demand and greenhouse gas (GHG) emissions of four propylene production pathways in China. J. Clean. Prod. 2017, 163, 285-292. [CrossRef] 
53. Xiang, D.; Qian, y.; Man, Y.; Yang, S.Y. Techno-economic analysis of the coal-to-olefines process in comparison with the oil-to-olefins process. Appl. Energy 2014, 113, 639-647. [CrossRef]

54. Compiled by National Bureau of Statistics of China. China Statistical Yearbook 2019. Available online: http://www.stats.gov.cn/tjsj/ndsj/2019/indexch.htm (accessed on 7 April 2020).

55. IEA. Prospects for Distributed Energy System in China. Available online: https://www.iea.org/reports/ prospects-for-distributed-energy-systems-in-china (accessed on 7 April 2020).

56. Pan, S.Y.; Lin, Y.J.; Snyder, S.W.; Ma, H.W. Development of low-carbon-driven bio-product technology using lignocellulosic substrates from agriculture: Challenges and perspectives. Curr. Sustain. Renew. Energy Rep. 2015, 2, 145-154. [CrossRef]

57. Li, P.; Pan, S.Y.; Pei, S.; Lin, Y.P.J.; Chiang, P.C. Challenges and perspectives on carbon fixation and utilization technologies: An overview. Aerosol Air Qual. Res. 2016, 16, 1327-1344. [CrossRef]

58. Li, Y.P.; Wang, W.H.; Pan, S.Y.; Ho, C.C.; Hou, J.C.; Chiang, P.C. Environmental impacts and benefits of organic Rankine cycle power generation technology and wood pellet fuel exemplified by electric arc furnace steel industry. Energy 2016, 183, 369-379.

(C) 2020 by the authors. Licensee MDPI, Basel, Switzerland. This article is an open access article distributed under the terms and conditions of the Creative Commons Attribution (CC BY) license (http://creativecommons.org/licenses/by/4.0/). 